\title{
Morphometric analysis of proinflammatory cytokines in mammary glands of sows suggests an association between clinical mastitis and local production of IL-1beta, IL-6 and TNF-alpha
}

\author{
Yaohong ZHU ${ }^{\mathrm{a}, \mathrm{b}}$, Caroline FossUM ${ }^{\mathrm{c}}$, Mikael BERG ${ }^{\mathrm{d}}$, Ulf MAGNUSSON ${ }^{\mathrm{a}, \mathrm{b} *}$ \\ ${ }^{a}$ Division of Reproduction, Department of Clinical Sciences, Faculty of Veterinary Medicine and \\ Animal Science, Swedish University of Agricultural Sciences, PO Box 7054, 75007 Uppsala, Sweden \\ ${ }^{\mathrm{b}}$ Centre for Reproductive Biology in Uppsala, Uppsala, Sweden \\ ${ }^{c}$ Division of Immunology, Department of Biomedical Sciences and Veterinary Public Health, \\ Swedish University of Agricultural Sciences, 75123 Uppsala, Sweden \\ ${ }^{\mathrm{d}}$ Division of Parasitology and Virology, Department of Biomedical Sciences and Veterinary Public \\ Health, Swedish University of Agricultural Sciences, 75007 Uppsala, Sweden
}

(Received 13 February 2007; accepted 11 June 2007)

\begin{abstract}
Twelve healthy primiparous sows received intramammary inoculation with Escherichia coli (serotype O127) during the 24-h period preceding parturition. Mammary gland biopsy samples were taken immediately before inoculation $(0 \mathrm{~h})$ and from the inoculated and the contralateral noninoculated glands $24 \mathrm{~h}$ after inoculation. The analyses of interleukin- 1 beta (IL-1 $\beta$ ), IL-6, IL-8, and tumor necrosis factor alpha (TNF- $\alpha$ ) by immunohistochemistry revealed that the production of these proinflammatory cytokines significantly increased in the inoculated mammary glands of sows that developed clinical signs of mastitis (affected group, $n=4$ ) $24 \mathrm{~h}$ after inoculation. This was also true for IL-8 in the inoculated mammary glands of sows that did not develop clinical signs of mastitis (nonaffected group, $n=8$ ). Sows that developed clinical signs of mastitis displayed significantly lower constitutive production of IL-1 $\beta$ than did sows that remained clinically healthy. The data indicate that the development of clinical symptoms of coliform mastitis in the sow is associated with a locally increased proinflammatory cytokine production in response to intramammary E. coli infection.
\end{abstract}

cytokine / immunohistochemistry / mastitis / pig / E. coli

\section{INTRODUCTION}

The proinflammatory cytokines mediate the early local and systemic responses to microbial challenges. These small proteins, including interleukin-1 beta (IL$1 \beta)$, IL-6, IL-8, and tumor necrosis fac-

\footnotetext{
* Corresponding author: ulf.magnusson@kv.slu.se
}

tor alpha (TNF- $\alpha)$, are released by various cell types such as monocytes, neutrophils, macrophages, lymphocytes, endothelial, and epithelial cells [12, 28, 34, $42,51,58]$, and play dual pathophysiological roles, as proinflammatory as well as immunoregulatory mediators $[3,18,31]$. This in turn makes them associate with symptoms of disease [10, 20, 52]. Even so, cytokines appear to be an important 
component of a paracrine/autocrine communication network in the mammary gland throughout the different stages of pregnancy and parturition $[25,44]$. It should be noted that a low constitutive production of some of these cytokines may take place in healthy individuals $[22,23,55]$.

During the development of mastitis, in the cow as well as in the sow, it has been shown that the proinflammatory cytokines not only provide defence against bacterial infections, but also contribute to the clinical symptoms of disease $[5,30,44,46,49$, $50,59]$. For instance, it has been established that IL-1 $\beta$, IL-6, IL- 8 , and TNF- $\alpha$ play a role in the initiation of the inflammatory responses following intramammary inoculation with Escherichia coli $[6,45,48$, 59]. Analyses of biopsies collected from mammary glands of sows inoculated with E. coli demonstrated the transcription of the genes for a number of proinflammatory cytokines, but analyses of IL-6 and TNF$\alpha$ in the same set of sows revealed that variations in serum/plasma concentrations were not reflected in the mRNA expression in mammary tissues $[59,60]$. This observation stresses the importance of relating observations at the mRNA level to the functional protein in order to understand the biological significance of the results and to disclose mechanisms of regulation. For instance, a diverse range of stimuli can affect IL-1 $\beta$, IL-6, IL-8 and TNF- $\alpha$ production and activity at various stages, including transcription, translation, cleavage and cellular release, or at the level of interaction with a receptor-mediated mechanism [2, 3, 17, 40]. As regards mastitis and cytokines the data are limited concerning the interrelationship between the local mRNA expression and protein production, and the systemic blood concentrations. Likewise, the knowledge about the association between the local amount of proinflammatory cytokines in the mammary gland and the outcome of infectious disease is scanty in domestic animals.
Therefore, the aim of the present study was to investigate the amount of proinflammatory cytokines such as IL-1 $\beta$, IL-6, IL-8, and TNF- $\alpha$ presented in mammary tissues of sows following intramammary inoculation with $E$. coli. The analyses were performed on biopsy material collected before and after inoculation with $E$. coli in sows that developed or did not develop clinical signs of mastitis. Cytokines were detected by immunohistochemistry (IHC) on cryostat sections and the amount of cytokine production was assessed by computerized image analysis.

\section{MATERIALS AND METHODS}

\subsection{Animals}

Twelve pregnant crossbred (Swedish Landrace $\times$ Yorkshire) primiparous sows were obtained from a commercial farm and used in the study [43]. Sows were obtained approximately 6 to 8 weeks before anticipated parturition. Clinical signs of mastitis or other diseases were not observed in any of the sows before the start of the study. Experimental procedures and housing conditions were approved by the Ethical Committee for Animal Experiments, Uppsala, Sweden.

\subsection{Experimental model and categorization of sows}

The experimental model and categorization of sows have been described in detail previously [43]. In brief, each teat on the right side of mammary glands (inoculated glands) was inoculated with $0.5 \mathrm{~mL}$ of bacterial suspension $\left(10^{5}\right.$ colony forming units $(\mathrm{CFU}) / \mathrm{mL})$ containing $E$. coli strain serotype $\mathrm{O} 127$ during the 24 -h period before parturition. The contralateral mammary glands were used for sampling from non-inoculated glands. Four of the inoculated sows developed prominent clinical 
Table I. Primary antibodies used in the immunohistochemical study.

\begin{tabular}{lccccc}
\hline Specificity & Source & $\mathrm{pAb} / \mathrm{mAb}$ & Company* & Catalogue no. & Dilution \\
\hline Anti-human IL-1 $\beta^{\mathrm{a}}$ & Rabbit & $\mathrm{pAb}$ & Endogen & P-420B & $1: 100$ \\
Anti-porcine IL-6 & Mouse & $\mathrm{mAb}$ & R \& D Systems & MAB686 & $1: 40$ \\
Anti-human IL-8 & Goat & $\mathrm{pAb}$ & R \& D Systems & AF-208-NA & $1: 50$ \\
Anti-porcine TNF- $\alpha$ & Goat & $\mathrm{pAb}$ & R \& D Systems & AF690 & $1: 50$ \\
\hline
\end{tabular}

IL-1 $\beta$, interleukin-1 $\beta$; TNF- $\alpha$, tumor necrosis factor $\alpha$; pAb, polyclonal antibody; mAb, monoclonal antibody.

${ }^{a}$ Rodriguez et al. [47].

* Endogen (Endogen, Woburn, MA, USA); R \& D Systems (R \& D Systems Europe Ltd., Abingdon, UK).

signs of mastitis (i.e. fever, lethargy, and swelling of $\geqslant 2$ mammary glands) $24 \mathrm{~h}$ after intramammary inoculation with $E$. coli, and were categorized as the affected group. The other eight inoculated sows did not develop clinical signs of mastitis, and were thus categorized as the non-affected group.

\subsection{Biopsy procedure}

The biopsy procedure was performed as previously described [35]. Briefly, two biopsies per mammary gland were carried out using a Bard Magnum ${ }^{\circledR}$ Biopsies instrument and a $(12 \mathrm{G} \times 10 \mathrm{~cm})$ core tissue biopsy needle (CR BARD Inc., Covington, GA, USA). Mammary gland biopsy was performed immediately before inoculation $(0 \mathrm{~h})$ and from the inoculated and the contralateral non-inoculated glands at $24 \mathrm{~h}$ after inoculation. The specimens were immediately frozen in liquid nitrogen and stored at $-80{ }^{\circ} \mathrm{C}$ until used for analyses.

\subsection{Immunohistochemistry}

Monoclonal or polyclonal antibodies combined with the avidin-biotinperoxidase complex (ABC) technique (Vectastain Elite ABC Kit, Vector Laboratories, Inc., Burlingame, CA, USA) was used for the immunohistochemical detection of IL-1 $\beta$, IL-8 [47], IL-6, and TNF- $\alpha$ (Tab. I). All samples from one animal were analysed within the same assay run, and within each assay run both affected and nonaffected animals were included.

Cryostat sections ( $7 \mu \mathrm{m}$ in thickness) were prepared from each biopsy sample, air dried and fixed in acetone for $10 \mathrm{~min}$ at room temperature. The slides were incubated two times for $30 \mathrm{~min}$ each at room temperature in Tris-buffered saline (TBS; $\mathrm{pH}$ 7.6) supplemented with $10 \%$ normal serum of the species from which the secondary antibody was produced. The sections were then incubated with the primary antibodies (Tab. I) overnight in a humidified chamber at $4{ }^{\circ} \mathrm{C}$.

Biotinylated antibodies at a dilution of 1:500 (goat anti-rabbit for IL-1 $\beta$, horse anti-mouse for IL-6, and rabbit anti-goat for IL- 8 and TNF- $\alpha$ ) were applied as secondary antibodies (Vectastain Elite ABC Kit, Vector Laboratories, Inc., Burlingame, CA, USA) for $30 \mathrm{~min}$ at room temperature. After washing $3 \times 5$ min with TBS, the slides were incubated for 20 min in $\mathrm{H}_{2} \mathrm{O}_{2}$ ( $0.3 \%$ in Methanol) to block endogenous peroxidase activity, and then washed three times. The slides were incubated with $\mathrm{ABC}$ reagent according to the manufacturer's instructions (Vectastain Elite ABC Kit, Vector Laboratories, Inc., Burlingame, CA, USA). After repeated washing in TBS, the slides were flooded with fleshly prepared 3, 3'-diaminobenzidine tetrahydrochloride (DAB Chromogen; DakoCytomation Denmark A/S, Glostrup, 
Denmark) containing $0.03 \% \quad \mathrm{H}_{2} \mathrm{O}_{2}$ to give a brown reaction product. The slides were counterstained with $10 \%$ Mayer's haematoxylin (VWR international $\mathrm{AB}$, Stockholm, Sweden) and mounted with glycerolgelatin. As negative controls, the primary antibodies were replaced by rabbit IgG, goat IgG (Jackson ImmunoResearch Laboratories, Inc., West Grove, PA, USA), or mouse IgG1 (Dakocytomation Denmark A/S, Glostrup, Denmark) at the same concentration as the corresponding primary antibody. To check the specificity of the secondary antibodies, the primary antibodies were replaced by TBS.

The DAB stained areas (the positively stained areas) in the sections were quantified using an image analysis software (Easy Image 3000, TEKNO OPTIK AB, Göteborg, Sweden). Five fields (magnification, $200 \times$ ) from each tissue sample (3 section slices were prepared from each sample) were captured using a Nikon Microphot FXA equipped with a Nikon DS$5 \mathrm{M}$ digital camera (Nikon, Japan). The DAB color-specific staining was determined by defining a threshold for hues and intensities that corresponded to those color attributes that were assessed as positive in five randomly selected samples within the same assay run, compared with negative controls. This spectral threshold was then used for analyzing all images for that particular cytokine within the same run of IHC. Hereby, an unbiased continuity of analysis across samples was achieved. For each sample, a relative value of the amount of cytokine produced was expressed as the average percentage of the positively stained areas in five view fields. These data were accordingly considered as semiquantitative.

\subsection{Statistical analysis}

All statistical evaluation was performed by the use of a computerized statistical software package (Version 9.1, SAS Institute Inc., Cary, NC, USA). Before analysis normality of data was assessed using the PROC UNIV. The fixed effect of sow category, mammary gland sample and the interaction between sow category and mammary sample were analysed by PROC MIXED. The random effect of sow within sow category was included in the statistical model. When there was an overall effect of sow category or mammary gland sample $(P<0.05)$, pairwise comparisons between the least-square means were made. $P$ values $<0.05$ were considered statistically significant.

\section{RESULTS}

Most of the samples obtained from sows $24 \mathrm{~h}$ after inoculation exhibited accumulation of leukocytes in alveolar lumina and stroma, compared with samples obtained from sows before inoculation. The cytokines IL-1 $\beta$, IL- 6 , IL- 8 , and TNF- $\alpha$ were detected in all mammary gland biopsies regardless of the samples were obtained from sows before or $24 \mathrm{~h}$ after intramammary inoculation with $E$. coli. IL-1 $\beta$ and IL-6 was mainly localized to epithelium surrounding the lobulo-alveoli and endothelium, both in the cells and adjacent to the cells, positive staining was also seen in leukocytes (e.g. alveolar lumina) (Figs. 1A and 2A). IL-8 was likewise localized to epithelium, endothelium, but also to leukocytes (e.g. in alveolar lumina) (Fig. 3A). The TNF- $\alpha$ localization was similar to IL-8, except that TNF- $\alpha$ was more scattered throughout the cell (Fig. 4A).

Computerized image analysis of the IHC staining indicated that in the nonaffected group, the amount of IL-1 $\beta$ produced remained unaltered in samples collected from either the contralateral non-inoculated or inoculated mammary glands $24 \mathrm{~h}$ after inoculation (Fig. 1B). In the affected group, the IL- $1 \beta$ produced 
A

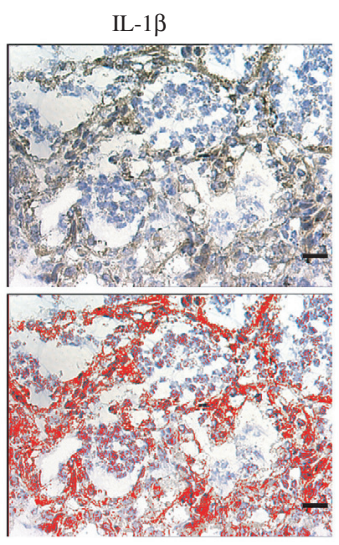

B

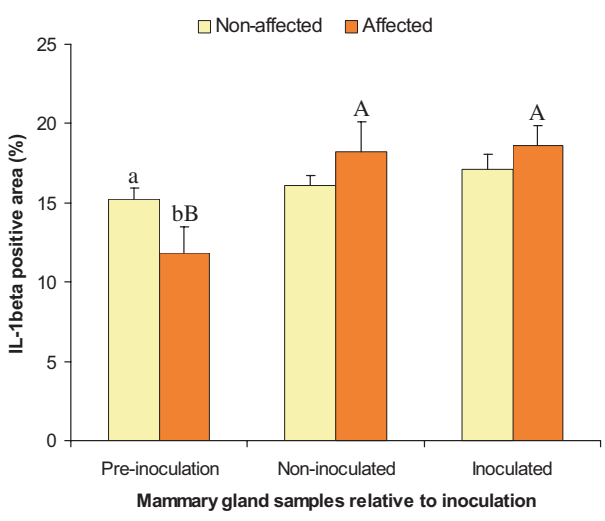

Figure 1. Immunohistochemical localization of IL-1 $\beta$ in mammary tissues collected from sows before and after inoculation with E. coli. (A), (Top panel) The microphotograph from one affected sow with the positive rabbit anti-human IL-1 $\beta$ primary antibody reaction visualized with DAB reaction (brown color). (Bottom panel) Representative output from the image analysis algorithm used to quantify specific DAB reaction (red color). The area positive (brown color) for IL- $1 \beta$ for each image was quantified by the use of Easy Image 3000 software (the threshold based on staining intensity and color). Scale bar, $20 \mu \mathrm{m}$. (B), IL-1 $\beta$ production is presented as the average percentage of the positively stained areas. Data are expressed as the mean \pm SEM. Within sow category, values with different capital letters (A, B) differ significantly $(P<0.05)$. Between sow category within type of mammary gland samples, values with different letters $(\mathrm{a}, \mathrm{b})$ differ significantly $(P<0.05)$. Non-affected group, $N=8$; Affected group, $N=4$. (Please consult www.vetres.org for a colour version of this figure.)

increased in samples collected from both the non-inoculated (1.5-fold, $P=0.0040)$ and inoculated mammary glands (1.6-fold, $P=0.0014) 24 \mathrm{~h}$ after inoculation. Notably, comparison between samples collected from the non-affected and affected groups before inoculation, revealed that the amount of IL-1 $\beta$ produced was less (1.3fold, $P=0.0449)$ in samples collected from sows that became affected by the inoculation than in samples collected from sows that remained clinically healthy.

In the non-affected group, the amount of IL- 6 produced remained unchanged in samples collected from either the noninoculated or inoculated mammary glands $24 \mathrm{~h}$ after inoculation (Fig. 2B). Also, in samples collected from the contralateral non-inoculated mammary glands from the affected group, the amount of IL-6 produced remained unaltered. In contrast, the IL-6 produced increased (1.2-fold, $P=0.0382$ ) in samples collected from the inoculated mammary glands from the affected group. There were no notable differences in the amount of IL-6 produced between the two groups of sows in any of the samples.

Twenty-four hours after inoculation, an increase in the IL- 8 produced was found in samples collected from the inoculated mammary glands from the nonaffected group (1.7-fold, $P=0.0065)$ as well as from the affected group (1.6-fold, $P=0.0438)$, but not in samples collected from the non-inoculated mammary glands from any of the groups (Fig. 3B). There were no differences in the amount of 
A

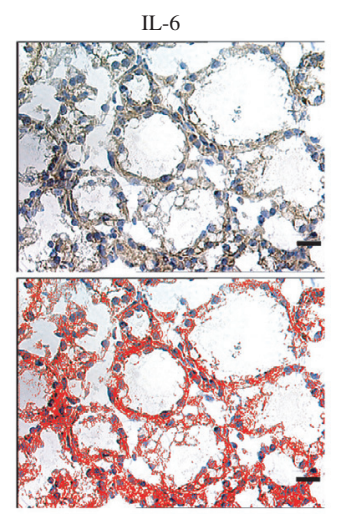

B

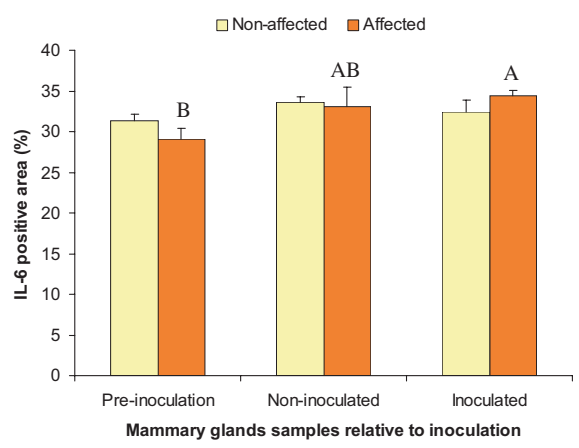

Figure 2. Immunohistochemical localization of IL-6 in mammary tissues collected from sows before and after inoculation with E. coli. (A), (Top panel) The microphotograph from one affected sow with the positive mouse anti-porcine IL-6 primary antibody reaction visualized with DAB reaction (brown color). (Bottom panel) Representative output from the image analysis algorithm used to quantify specific DAB reaction (red color). The area positive (brown color) for IL-6 for each image was quantified by the use of Easy Image 3000 software (the threshold based on staining intensity and color). Scale bar, $20 \mu \mathrm{m}$. (B), IL-6 production is presented as the average percentage of the positively stained areas. Data are expressed as the mean \pm SEM. See Figure 1 for key. Non-affected group, $N=8$; Affected group, $N=4$. (Please consult www.vetres.org for a colour version of this figure.)

IL-8 produced between the two groups in samples collected from either the preinoculation or inoculated mammary glands $24 \mathrm{~h}$ after inoculation.

In the non-affected group, the TNF- $\alpha$ produced remained unchanged in samples collected from either the non-inoculated or inoculated mammary glands $24 \mathrm{~h}$ after inoculation (Fig. 4B). In contrast, the TNF- $\alpha$ produced increased (1.4-fold, $P=0.0459$ ) in samples collected from the inoculated mammary glands from the affected group $24 \mathrm{~h}$ after inoculation.

\section{DISCUSSION}

The earliest and most potent proinflammatory cytokine released by the host in response to infection, has an essential role in the development of infectious disease [15, $16,39,40]$. Here we show that proinflammatory cytokines can be constitutively produced in mammary glands of healthy sows at parturition. Following intramammary inoculation with $E$. coli, we found a significant increase in the proinflammatory cytokine production in the inoculated mammary glands of sows that developed clinical signs of mastitis.

The cytokines were found both in the cytoplasmic compartments and scattered throughout the cells in mammary tissues. A similar distribution has been reported for TNF- $\alpha$ in human breast cancer tissues [9]. For such distribution of immunoreactive proteins, computerized image analysis is far more reproducible than manual scoring in assessing positive areas [19,27]. Even so, immunohistochemistry is only a semiquantitative assessment of the amount of cytokine, and gives a relative measurement implying that comparisons between the various cytokines are not possible. 
A

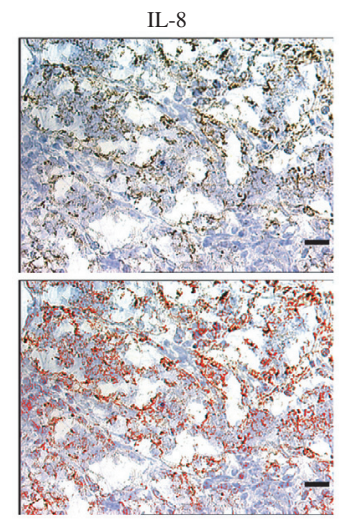

B

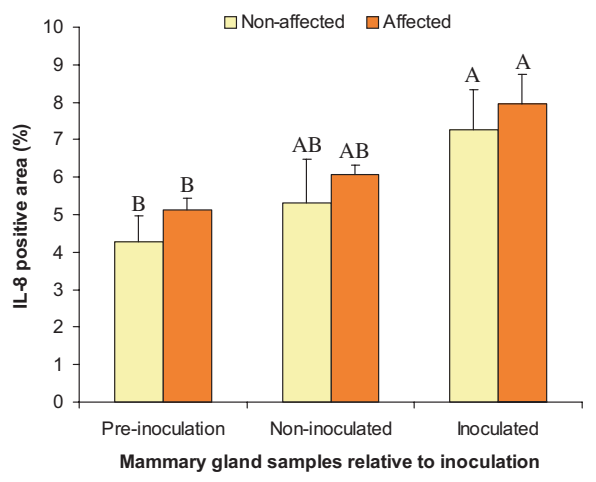

Figure 3. Immunohistochemical localization of IL-8 in mammary tissues collected from sows before and after inoculation with E. coli. (A), (Top panel) The microphotograph from one affected sow with the positive goat anti-human IL-8 primary antibody reaction with visualized with DAB reaction (brown color). (Bottom panel) Representative output from the image analysis algorithm used to quantify specific DAB reaction (red color). The area positive (brown color) for IL-8 for each image was quantified by the use of Easy Image 3000 software (the threshold based on staining intensity and color). Scale bar, $20 \mu \mathrm{m}$. (B), IL-8 production is presented as the average percentage of the positively stained areas. Data are expressed as the mean \pm SEM. See Figure 1 for key. Non-affected group, $N=8$; Affected group, $N=4$. (Please consult www.vetres.org for a colour version of this figure.)

Consistent with the constitutive mRNAexpression of proinflammatory cytokines in mammary tissues [60], the proinflammatory cytokine production here was also seen in mammary tissues obtained from sows before inoculation with $E$. coli. These findings are consistent with previous studies in rats, humans as well as in cows where some baseline constitutive production of cytokines takes place in normal mammary glands [7, 23, 56]. Similarly, proinflammatory cytokines have also been found in serum/plasma collected from healthy pregnant sows [59] as well as pregnant women $[4,24,57]$. The proinflammatory cytokines have been proposed to play a physiological role at parturition by being involved in the regulation of the parturition as such $[13,29]$. Also, cytokines appear to be an important component of a paracrine/autocrine communication net- work in the mammary gland at different stages of pregnancy and parturition [25, 44].

Interestingly, we found that the constitutive production of IL-1 $\beta$ at both the mRNA [60] and protein level here was lower in the mammary glands of sows that developed clinical signs of mastitis compared with sows that remained clinically healthy. A number of reports have suggested that IL- $1 \beta$ is essential for host defence against a variety of infectious challenges $[14,18,38]$. The underlying mechanisms of this remain at large unknown, even though it has been reported that IL-1 is necessary to stimulate the production of chemokine attractants for neutrophils such as macrophage inflammatory protein-2 (MIP2) and IL-8, which in turn recruit neutrophils to the site of infection, an event required for bacterial clearance 
A

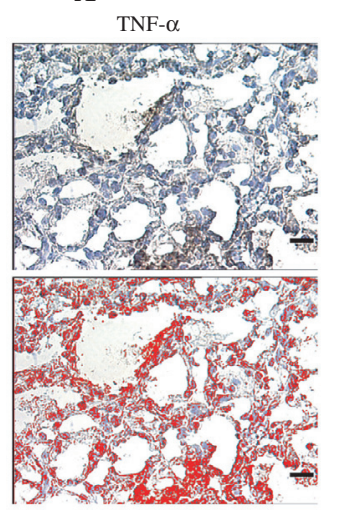

B

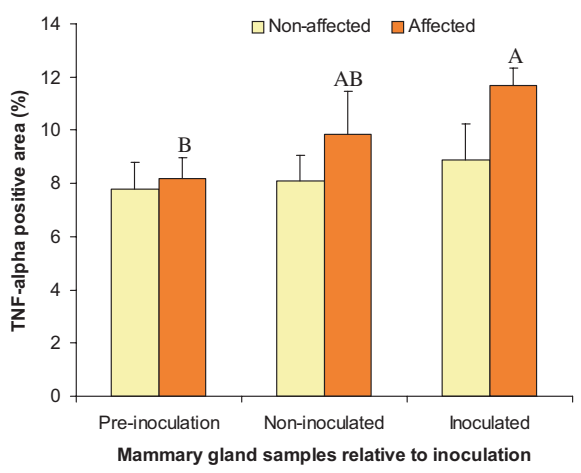

Figure 4. Immunohistochemical localization of TNF- $\alpha$ in mammary tissues collected from sows before and after inoculation with E. coli. (A), (Top panel) The microphotograph from one affected sow with the positive goat anti-porcine TNF- $\alpha$ primary antibody reaction visualized with DAB reaction (brown color). (Bottom panel) Representative output from the image analysis algorithm used to quantify specific DAB reaction (red color). The area positive (brown color) for TNF- $\alpha$ for each image was quantified by the use of Easy Image 3000 software (the threshold based on staining intensity and color). Scale bar, $20 \mu \mathrm{m}$. (B), TNF- $\alpha$ production is presented as the average percentage of the positively stained areas. Data are expressed as the mean \pm SEM. See Figure 1 for key. Nonaffected group, $N=8$; Affected group, $N=4$. (Please consult www.vetres.org for a colour version of this figure.)

[21]. Thus, these earlier data and the data presented here call for further studies to elucidate a possible role of IL- $1 \beta$ in protection against coliform mastitis.

The analysis of proinflammatory cytokine production by immunohistochemistry revealed that the production of IL- $1 \beta$, IL-6, IL-8, and TNF- $\alpha$ significantly increased in the inoculated mammary glands of sows that developed clinical signs of mastitis $24 \mathrm{~h}$ after intramammary inoculation with $E$. coli, and for IL-8, an increased production was also found in the inoculated mammary glands of sows that did not develop clinical signs of mastitis. These results are consistent with a previous study on those cytokine mRNA expression in mammary tissues obtained from the same set of sows [60]. Notably, the increased production of IL- $1 \beta$, IL- 6 , and TNF- $\alpha$ was not seen in the inoculated mammary glands of sows that remained clinically healthy $24 \mathrm{~h}$ after inoculation, although an increased expression of TNF- $\alpha$ was found at the mRNA level [60]. Possibly, in these sows there may be abundant and regulated release of anti-inflammatory mediators $[40,53]$, limiting the production of the inflammatory cytokines. However, in accordance with our results, previous studies in cows have shown a significant increase in the proinflammatory cytokines at the level of both mRNA [33,37] and protein $[6,11,26,32,45,48,54]$ in either mammary tissues or milk collected from the infected glands following intramammary inoculation with $E$. coli. The results here indicate that the development of clinical symptoms of coliform mastitis in the sow is associated with a locally increased proinflammatory cytokine production in response to intramammary $E$. coli infection. Regarding IL-8, an increased production was found in the inoculated mammary 
glands of both sows that did or did not develop clinical signs of mastitis. This may be interpreted as IL-8 has a physiological role in the lactating porcine mammary gland to attract neutrophils, which is supported by data in other species and by data showing that colostrum collected from healthy sows contains a high proportion neutrophils $[36,41]$.

Previously we have shown that the concentrations of IL- 6 and TNF- $\alpha$ in blood were higher in sows that developed clinical signs of mastitis compared with sows that remained clinically healthy $24 \mathrm{~h}$ after intramammary inoculation with E. coli [59], whereas no differences were found in IL-6 and TNF- $\alpha$ mRNA expression in infected mammary glands between the two groups [60]. The observations here, including the same set of sows, are in accordance with the mRNA data, i.e. the production of these proinflammatory cytokines in inoculated mammary glands did not differ between the two groups. Possible explanation for this discrepancy between systemic and local proinflammatory cytokine levels might be that proinflammatory cytokines could also be produced elsewhere but the site of bacterial inoculation $[1,8,12,15]$. Alternatively, there might be a larger diffusion of cytokines into the blood in the sows with clinical signs of mastitis attributable to the inflammatory damage of mammary glands.

In the present study only one third of the inoculated sows developed clinical mastitis. Previously we have not been able to show an impaired function of granulocytes before inoculation, the cells crucial in bacterial clearance in the mammary gland, in the sows that developed clinical signs of mastitis [43]. This study on the events preceding the granulocyte response, revealed that the production of IL$1 \beta$, IL- 6 , IL- 8 , and TNF- $\alpha$ significantly increased in the inoculated mammary glands of sows that were clinically affected by intramammary infection with $E$. coli. In addition, we found that there were lower levels of constitutively produced IL- $1 \beta$ in mammary glands of sows that developed clinical signs of mastitis compared with sows that remained clinically healthy. The data indicate that the development of clinical symptoms of coliform mastitis in the sow is associated with a locally increased proinflammatory cytokine production in response to intramammary $E$. coli infection.

\section{ACKNOWLEDGEMENTS}

This work was supported by the Swedish Research Council for Environment, Agricultural Sciences and Spatial Planning and the Programme for Infection Biology at the Faculty of Veterinary Medicine and Animal Science, Swedish University of Agricultural Sciences. Drs M. Löving and I. Österlundh are greatly acknowledged for providing the biopsy specimens.

\section{REFERENCES}

[1] Akira S., Uematsu S., Takeuchi O., Pathogen recognition and innate immunity, Cell (2006) 124:783-801.

[2] Albee L., Perlman H., E. coli infection induces caspase dependent degradation of NF-kappaB and reduces the inflammatory response in macrophages, Inflamm. Res. (2006) 55:2-9.

[3] Allan S.M., Tyrrell P.J., Rothwell N.J., Interleukin-1 and neuronal injury, Nat. Rev. Immunol. (2005) 5:629-640.

[4] Bahar A.M., Ghalib H.W., Moosa R.A., Zaki Z.M., Thomas C., Nabri O.A., Maternal serum interleukin-6, interleukin-8, tumor necrosis factor-alpha and interferon-gamma in preterm labor, Acta Obstet. Gynecol. Scand. (2003) 82:543-549.

[5] Bannerman D.D., Paape M.J., Goff J.P., Kimura K., Lippolis J.D., Hope J.C., Innate immune response to intramammary infection with Serratia marcescens and Streptococcus uberis, Vet. Res. (2004) 35:681-700.

[6] Bannerman D.D., Paape M.J., Lee J.W., Zhao X., Hope J.C., Rainard P., Escherichia 
coli and Staphylococcus aureus elicit differential innate immune responses following intramammary infection, Clin. Diagn. Lab. Immunol. (2004) 11:463-472.

[7] Basolo F., Conaldi P.G., Fiore L., Calvo S., Toniolo A., Normal breast epithelial cells produce interleukins 6 and 8 together with tumor-necrosis factor: defective IL6 expression in mammary carcinoma, Int. J. Cancer (1993) 55:926-930.

[8] Baumann H., Gauldie J., The acute phase response, Immunol. Today (1994) 15:74-80.

[9] Bebok Z., Markus B., Nemeth P., Prognostic relevance of transforming growth factor alpha (TGF-alpha) and tumor necrosis factor alpha (TNF-alpha) detected in breast cancer tissues by immunohistochemistry, Breast Cancer Res. Treat. (1994) 29:229-235.

[10] Beutler B., Rietschel E.T., Innate immune sensing and its roots: the story of endotoxin, Nat. Rev. Immunol. (2003) 3:169-176.

[11] Blum J.W., Dosogne H., Hoeben D., Vangroenweghe F., Hammon H.M., Bruckmaier R.M., Burvenich C., Tumor necrosis factor-alpha and nitrite/nitrate responses during acute mastitis induced by Escherichia coli infection and endotoxin in dairy cows, Domest. Anim. Endocrinol. (2000) 19:223-235.

[12] Borish L.C., Steinke J.W., 2. Cytokines and chemokines, J. Allergy Clin. Immunol. (2003) 111 Suppl.:S460-S475.

[13] Bowen J.M., Chamley L., Keelan J.A., Mitchell M.D., Cytokines of the placenta and extra-placental membranes: roles and regulation during human pregnancy and parturition, Placenta (2002) 23:257-273.

[14] Burvenich C., Van Merris V., Mehrzad J., Diez-Fraile A., Duchateau L., Severity of $E$. coli mastitis is mainly determined by cow factors, Vet. Res. (2003) 34:521-564.

[15] Cohen J., The immunopathogenesis of sepsis, Nature (2002) 420:885-891.

[16] Coussens L.M., Werb Z., Inflammation and cancer, Nature (2002) 420:860-867.

[17] De Groot J., Kruijt L., Scholten J.W., Boersma W.J., Buist W.G., Engel B., van Reenen C.G., Age, gender and litter-related variation in T-lymphocyte cytokine production in young pigs, Immunology (2005) 115:495-505.

[18] Dinarello C.A., Interleukin 1 and interleukin 18 as mediators of inflammation and the aging process, Am. J. Clin. Nutr. (2006) 83:447S-455S.
[19] Elsasser T.H., Kahl S., MacLeod C., Nicholson B., Sartin J.L., Li C., Mechanisms underlying growth hormone effects in augmenting nitric oxide production and protein tyrosine nitration during endotoxin challenge, Endocrinology (2004) 145:3413-3423.

[20] Fournout S., Dozois C.M., Odin M., Desautels C., Peres S., Herault F., Daigle F., Segafredo C., Laffitte J., Oswald E., Fairbrother J.M., Oswald I.P., Lack of a role of cytotoxic necrotizing factor 1 toxin from Escherichia coli in bacterial pathogenicity and host cytokine response in infected germfree piglets, Infect. Immun. (2000) 68:839-847.

[21] Gamero A.M., Oppenheim J.J., IL-1 can act as number one, Immunity (2006) 24:16-17.

[22] Green A.R., Green V.L., White M.C., Speirs V., Expression of cytokine messenger RNA in normal and neoplastic human breast tissue: identification of interleukin-8 as a potential regulatory factor in breast tumours, Int. J. Cancer (1997) 72:937-941.

[23] Hagiwara K., Kataoka S., Yamanaka H., Kirisawa R., Iwai H., Detection of cytokines in bovine colostrum, Vet. Immunol. Immunopathol. (2000) 76:183-190.

[24] Hebisch G., Neumaier-Wagner P.M., Huch R., von Mandach U., Maternal serum interleukin-1 beta, -6 and -8 levels and potential determinants in pregnancy and peripartum, J. Perinat. Med. (2004) 32:475-480.

[25] Hennighausen L., Robinson G.W., Information networks in the mammary gland, Nat. Rev. Mol. Cell Biol. (2005) 6:715-725.

[26] Hoeben D., Burvenich C., Trevisi E., Bertoni G., Hamann J., Bruckmaier R.M., Blum J.W., Role of endotoxin and TNF-alpha in the pathogenesis of experimentally induced coliform mastitis in periparturient cows, J. Dairy Res. (2000) 67:503-514.

[27] Huse M., Lillemeier B.F., Kuhns M.S., Chen D.S., Davis M.M., T cells use two directionally distinct pathways for cytokine secretion, Nat. Immunol. (2006) 7:247-255.

[28] Itoh K., Udagawa N., Kobayashi K., Suda K., Li X., Takami M., Okahashi N., Nishihara T., Takahashi N., Lipopolysaccharide promotes the survival of osteoclasts via Toll-like receptor 4 , but cytokine production of osteoclasts in response to lipopolysaccharide is different from that of macrophages, J. Immunol. (2003) 170:3688-3695. 
[29] Keelan J.A., Blumenstein M., Helliwell R.J., Sato T.A., Marvin K.W., Mitchell M.D., Cytokines, prostaglandins and parturition-a review, Placenta (2003) 24 Suppl. A:S33S46.

[30] Kehrli M.E. Jr., Harp J.A., Immunity in the mammary gland, Vet. Clin. North Am. Food Anim. Pract. (2001) 17:495-516.

[31] Kodama S., Davis M., Faustman D.L., The therapeutic potential of tumor necrosis factor for autoimmune disease: a mechanistically based hypothesis, Cell. Mol. Life Sci. (2005) 62:1850-1862.

[32] Lee J.W., Paape M.J., Elsasser T.H., Zhao X., Recombinant soluble CD14 reduces severity of intramammary infection by Escherichia coli, Infect. Immun. (2003) 71:4034-4039.

[33] Lee J.W., Bannerman D.D., Paape M.J., Huang M.K., Zhao X., Characterization of cytokine expression in milk somatic cells during intramammary infections with Escherichia coli or Staphylococcus aureus by real-time PCR, Vet. Res. (2006) 37:219_ 229.

[34] Lekstrom-Himes J.A., Kuhns D.B., Alvord W.G., Gallin J.I., Inhibition of human neutrophil IL- 8 production by hydrogen peroxide and dysregulation in chronic granulomatous disease, J. Immunol. (2005) 174:411417.

[35] Loving M., Magnusson U., Sows intramammarily inoculated with Escherichia coli at parturition. II. Effects on the densities of $\mathrm{MHC}$ class $\mathrm{II}(+), \mathrm{CD} 4(+)$ and $\mathrm{CD} 8(+)$ cells in the mammary gland, Vet. Immunol. Immunopathol. (2002) 90:45-54.

[36] Magnusson U., Rodriguez-Martinez H., Einarsson S., A simple, rapid method for differential cell counts in porcine mammary secretions, Vet. Rec. (1991) 129:485-490.

[37] McClenahan D., Krueger R., Lee H.Y., Thomas C., Kehrli M.E. Jr., Czuprynski C., Interleukin-8 expression by mammary gland endothelial and epithelial cells following experimental mastitis infection with $E$. coli, Comp. Immunol. Microbiol. Infect. Dis. (2006) 29:127-137.

[38] Miller L.S., O'Connell R.M., Gutierrez M.A., Pietras E.M., Shahangian A., Gross C.E., Thirumala A., Cheung A.L., Cheng G., Modlin R.L., MyD88 mediates neutrophil recruitment initiated by $\mathrm{IL}-1 \mathrm{R}$ but not TLR2 activation in immunity against Staphylococcus aureus, Immunity (2006) 24:79-91.
[39] Murray R.Z., Kay J.G., Sangermani D.G., Stow J.L., A role for the phagosome in cytokine secretion, Science (2005) 310:14921495.

[40] Nathan C., Points of control in inflammation, Nature (2002) 420:846-852.

[41] Negus R.P., The chemokines: cytokines that direct leukocyte migration, J. R. Soc. Med. (1996) 89:312-314.

[42] Netea M.G., Gijzen K., Coolen N., Verschueren I., Figdor C., Van der Meer J.W., Torensma R., Kullberg B.J., Human dendritic cells are less potent at killing Candida albicans than both monocytes and macrophages, Microbes Infect. (2004) 6:985-989.

[43] Osterlundh I., Hulten F., Johannisson A., Magnusson U., Sows intramammarily inoculated with Escherichia coli at parturition: I. Functional capacity of granulocytes in sows affected or non-affected by clinical mastitis, Vet. Immunol. Immunopathol. (2002) 90:35-44.

[44] Rainard P., Riollet C., Innate immunity of the bovine mammary gland, Vet. Res. (2006) 37:369-400

[45] Riollet C., Rainard P., Poutrel B., Differential induction of complement fragment C5a and inflammatory cytokines during intramammary infections with Escherichia coli and Staphylococcus aureus, Clin. Diagn. Lab. Immunol. (2000) 7:161-167.

[46] Riollet C., Rainard P., Poutrel B., Cells and cytokines in inflammatory secretions of bovine mammary gland, Adv. Exp. Med. Biol. (2000) 480:247-258.

[47] Rodriguez F., Ramirez G.A., Sarradell J., Andrada M., Lorenzo H., Immunohistochemical labelling of cytokines in lung lesions of pigs naturally infected with Mycoplasma hyopneumoniae, J. Comp. Pathol. (2004) 130:306-312.

[48] Shuster D.E., Kehrli M.E. Jr., Rainard P., Paape M., Complement fragment C5a and inflammatory cytokines in neutrophil recruitment during intramammary infection with Escherichia coli, Infect. Immun. (1997) 65:3286-3292.

[49] Sordillo L.M., Shafer-Weaver K., DeRosa D., Immunobiology of the mammary gland, J. Dairy Sci. (1997) 80:1851-1865.

[50] Sordillo L.M., Streicher K.L., Mammary gland immunity and mastitis susceptibility, J. Mammary Gland Biol. Neoplasia (2002) 7:135-146. 
[51] Stadnyk A.W., Cytokine production by epithelial cells, FASEB J. (1994) 8:1041-1047.

[52] Svanborg C., Godaly G., Hedlund M., Cytokine responses during mucosal infections: role in disease pathogenesis and host defence, Curr. Opin. Microbiol. (1999) 2:99_ 105.

[53] Tracey K.J., The inflammatory reflex, Nature (2002) 420:853-859.

[54] Vangroenweghe F., Duchateau L., Burvenich C., Moderate inflammatory reaction during experimental Escherichia coli mastitis in primiparous cows, J. Dairy Sci. (2004) 87:886-895.

[55] Vangroenweghe F., Lamote I., Burvenich C., Physiology of the periparturient period and its relation to severity of clinical mastitis, Domest. Anim. Endocrinol. (2005) 29:283293.

[56] Varela L.M., Ip M.M., Tumor necrosis factor-alpha: a multifunctional regulator of mammary gland development, Endocrinology (1996) 137:4915-4924.
[57] Vassiliadis S., Ranella A., Papadimitriou L., Makrygiannakis A., Athanassakis I., Serum levels of pro- and anti-inflammatory cytokines in non-pregnant women, during pregnancy, labour and abortion, Mediators Inflamm. (1998) 7:69-72.

[58] Wellnitz O., Kerr D.E., Cryopreserved bovine mammary cells to model epithelial response to infection, Vet. Immunol. Immunopathol. (2004) 101:191-202.

[59] Zhu Y., Osterlundh I., Hulten F., Magnusson U., Tumor necrosis factor-alpha, interleukin6, serum amyloid A, haptoglobin, and cortisol concentrations in sows following intramammary inoculation of Escherichia coli, Am. J. Vet. Res. (2004) 65:1434-1439.

[60] Zhu Y., Berg M., Fossum C., Magnusson U., Proinflammatory cytokine mRNA expression in mammary tissue of sows following intramammary inoculation with Escherichia coli, Vet. Immunol. Immunopathol. (2007) 116:98-103. 